\title{
Tapping panel diagnosis, an innovative on-farm decision support system for rubber tree tapping
}

\author{
Thierry Michels • Jean-Marie Eschbach • Régis Lacote • \\ Aurore Benneveau • François Papy
}

Accepted: 25 November 2011 / Published online: 29 December 2011

(C) INRA and Springer-Verlag, France 2011

\begin{abstract}
Latex is a key product for many tropical countries, of which $80 \%$ is produced by smallholders. Latex is produced by the rubber tree (Hevea brasiliensis). Given the 7-year immature unproductive period, establishing a rubber plantation requires considerable investment by smallholders, emphasizing the need for sustainable management. The difficulty of performing an agronomic diagnosis of a tree crop is to obtain an accurate picture of current and past cultivation practices, to be able to assess their impacts on the agro-ecosystem as well as on sustainability. Smallholders do not usually keep records of latex yield or of their technical practices, making it impossible to perform a diagnosis based on productivity. As latex harvesting involves tapping the bark, which leaves scars on the trunk, we hypothesised that these morphological traces would be good indicators of current and past practices and would thus enable a diagnosis based on the economic lifespan of plantation. To this end, we formalised a tapping panel diagnosis that involved reproducing the scars on tapping panel diagrams, and analysing them using two indicators: the amount of virgin bark consumed and the number of tapping years that remained. We validated this tapping panel diagnosis in a sample of 25 smallholder plantations in Cameroon, where we characterised
\end{abstract}

T. Michels $(\bowtie) \cdot$ A. Benneveau

CIRAD, UPR HortSys,

BP 180, 97455 Saint Pierre Cedex, La Réunion, France

e-mail: michels@cirad.fr

J.-M. Eschbach • R. Lacote

CIRAD, UPR Systèmes de pérenne,

34398 Montpellier Cedex 5, France

F. Papy

INRA, UMR SAD-APT,

78850 Thiverval Grignon, France eight tapping management systems reflecting different levels of tapping intensity. The assessment of the respective share of each tapping practice on virgin bark consumption revealed major effects of tapping frequency and of shaving thickness. We showed that the tapping panel diagnosis used as a decision support tool can increase remaining tapping years by $33 \%$ to $355 \%$. To conclude, the tapping panel diagnosis formalised here for the first time will be a useful support for the participatory development of innovating tapping management schemes involving both technicians and smallholders.

Keywords Hevea brasiliensis · Natural rubber · Latex · Diagnosis tool · Sustainability · Smallholder $\cdot$ On-farm research $\cdot$ Economic lifespan $\cdot$ Cameroon

\section{Introduction}

Natural rubber, or latex, is a key product for many tropical countries in Asia, South America and Africa, and $80 \%$ of latex is produced on smallholder plantations covering more than $2,300,000$ ha (IRSG 2010). Worldwide demand for natural rubber is increasing. Compared with synthetic rubber, the demand for natural rubber has increased by $5 \%$ during the last decade and reached $44.4 \%$ in 2009 (IRSG 2010), leading to the expansion of rubber tree (Hevea brasiliensis) farms. Three main factors underline the current need for sustainable management of rubber tree plantations: the low standard of living of small-scale rubber producers, the high price of certified planting material (Michels 2005), and the long immature period of the plantation, which is about 7 years (Compagnon 1986; Webster and Baulkwill 1989).

Today, whatever the crop produced and the farming area of the world, agronomists and farmers are expected to both 
assess cropping systems and to design management practices to achieve sustainable agriculture (Lichtfouse et al. 2009). These expectations have led researchers to design diagnostic methods to identify the origin of an agronomic problem after the event (Doré et al. 1997, 2008) and, when necessary, to provide tools to help farmers to make technical decisions (Meynard et al. 2002; Chatelin et al. 2005) at the scale of both the plot and the territory (Nesme et al. 2010). Such approaches require the identification of the range of farmers' practices, their impact on agronomic performances, as well as ways of improving them. To this end, many studies have been conducted on annual crops, using methods such as oral surveys or monitoring networks of plots with the aim of reconstructing past cultivation practices (Gras et al. 1989; Doré et al. 1997; Affholder et al. 2003; Le Bail and Meynard 2003). But fewer studies have focused on perennial crops. The rare studies that focused on the long-term determinants of orchard performance were conducted in developed countries where the availability of long-term records of farmers' practices and yield make this possible (Nesme et al. 2003). The aim of these studies was to facilitate decision making by providing tools based on databases (Plénet et al. 2009). However, the scarcity of traces left by past practices on trees has prevented researchers from designing on-farm diagnostic tools based on the observation of trees. In addition, good research conditions are seldom found in developing countries in tropical regions where smallholders do not keep records of their practices or of yield, either for annual or perennial crops. Moreover, information based on a farmer's recollection of plot management over several years is often not entirely reliable.

In the case of rubber trees, latex is extracted using a multiannual tapping system that may last 15 to 30 years or more (Fig. 1). Observation of consumed bark area can provide essential and reliable information about the technical history of the plot. Agro-industrial experts, who study the links between the tapping management and the physiological condition of rubber trees, are accustomed to observing the bark and "reading" tapping panels to interpret latex production and to perform agronomic diagnoses. However, this method, which requires expensive analysis, is not suitable for smallholders. We thus hypothesised that extending and formalising agroindustrial know-how could help develop a diagnostic tool which would focus primarily on bark management and its impact on the economic lifespan of plantations. To be easy to use, the tool would require easily accessible data: bark observation and tapping panel analysis. As a decision support tool, it would help smallholders evaluate their technical choices and the potential consequences of their choices for the sustainability of the plantation.

Such a tool is all the more innovative as - to our knowledge - there are no studies in the literature on the use of morphological indicators to reconstruct the history of the

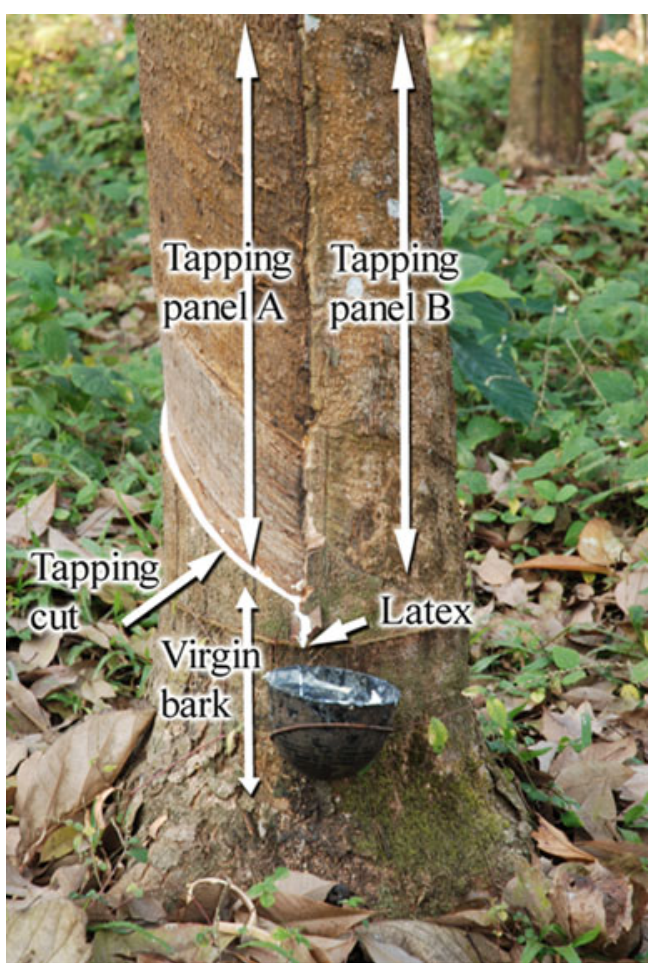

Fig. 1 Rubber tree latex is extracted using a multi-annual tapping system, which consists in using a gouge or a knife to cut away successive thin slices of trunk bark (bark shaving) at regular intervals of one or more days over a period of several decades. Tapping is usually stopped during the period of defoliation of the trees, i.e., for 30 days. Tapping leaves scars on the bark of the trunk. In the figure, tapping is conducted in a downward half spiral; the trunk is then separated into two tapping panels, A and B. Each renewal of the tapping cut causes latex to ooze all along the cut, which also serves as a gutter; the latex is then channeled towards a cup thanks to the slope of the tapping cut

practices applied throughout the lifespan of an orchard or plantation. This approach could be of great interest for rubber tree and also for less frequently studied species like oleo-gum resin trees (Lemenih et al. 2003; Ballal et al. 2005).

To this end, our study aimed to (1) formalise the principles of tapping panel diagnosis, and (2) validate this decision support tool in different rubber plantations in south-western Cameroon. First, we used the tapping panel diagnosis to characterise the range of tapping management strategies. Second, we evaluated the tapping panel diagnosis as a decisionsupport tool with the aim of helping smallholders to adopt more sustainable tapping systems.

\section{Materials and methods}

\subsection{Rubber tree tapping}

Here, we first describe the different parameters of tapping systems which are used as input variables in tapping panel 
diagnoses. Interactions between technical operations, or practices, relating to these parameters are exemplified through the description of tapping panel management systems.

\subsubsection{The input data: tapping practices and notations}

Figure 1 shows the tapping panel, i.e., the area of bark where the tapping cut is made. Tapping is commonly characterised by four technical parameters: the length and the direction of the tapping cut, the tapping frequency, and bark consumption (Vijayakumar et al. 2000).

The length of a tapping cut is expressed according to international notation as a portion of the trunk spiral: $\mathrm{S}$ for complete spiral, $\mathrm{S} / 2$ for half spiral, $\mathrm{S} / 3, \mathrm{~S} / 4$ (Vijayakumar et al. 2009). Tapping can be downward, where the area of consumed bark is located above the cut, or upward, where the area of consumed bark is located below the cut.

The tapping cut is renewed at regular intervals, expressed according to international notation as the number of days between two successive tapping cuts: $\mathrm{d} 1$ (every day), $\mathrm{d} 2$ (alternate daily tapping, once in 2 days), $\mathrm{d} 3$ (third daily tapping, once in 2 days), d4 (fourth daily tapping, once in 4 days), d5 (fifth daily tapping, once in 5 days), etc. This notation is supplemented by the number of workdays per week $-6 \mathrm{~d} / 7$, i.e., six working days out of seven (Vijayakumar et al. 2009).

The tapping frequency used by the farmer can be deduced by looking at the tapping panel. The number of tappings per year can be estimated by dividing the total height of consumed bark by the thickness of the bark shaving and by the number of tapping years. Nowadays, planters apply an ethylene generator to the tapping panel, which makes it possible to increase latex yield while reducing tapping frequency from $\mathrm{d} 2$ or $\mathrm{d} 3$ to $\mathrm{d} 4 \mathrm{~d}$ or $\mathrm{d} 5$. This practice, called hormone stimulation, considerably increases the economic sustainability of a plot, as well as yield and plantation productivity (Eschbach and Banchi 1985; Vijayakumar et al. 2001; Vijayakumar et al. 2003; Lacote et al. 2010).

The bark shaving is left at the foot of the tree. Ideally, it should be about $1.5-2 \mathrm{~mm}$ thick. The thickness of bark shaving is an indicator of tapping quality: A thicker bark shaving implies bark is being wasted with negative consequences for the economic sustainability of the tree. As the thickness depends on the skill of the tapper, it can vary from one plot to another.

\subsubsection{Connections between tapping practices: tapping management systems}

Tapping management includes opening height, cut length, tapping frequency, and the order of panel consumption.

The tree is usually tapped in two stages. The first stage involves downward tapping on the lower part of the trunk for ergonomic and productivity reasons as it leaves the upper section of trunk enough time to reach a satisfactory circumference for tapping. A downward tapping cut of a half-spiral $(\mathrm{S} / 2)$ is considered to be the best compromise between yield and sustainability (Compagnon 1986). Once the lower panels have been consumed, the upper section of the trunk can be tapped upward: This is the second stage, which starts at the height of the first cut made for downward tapping. During this stage, the tree generally responds better to hormonal stimulation and yield is higher (Obouayeba et al. 2009). Commère and Eschbach (1988a, b) showed that a high yield could be obtained by combining shorter tapping cuts with hormonal stimulation. For upward tapping, these authors determined a length of a tapping cut of a quarter spiral $(\mathrm{S} / 4)$ as the best compromise between plot productivity and sustainability.

Although it would be possible to tap several panels at the same time, only one cut at a time is recommended. This reduces bark consumption and leaves time for the consumed bark to regenerate so that the tapping panel can be tapped again 10 to 15 years later. The physiological balance of the tree is also preserved, as latex regeneration uses up the carbon resources of the tree (Silpi et al. 2007). Multiplying tapping cuts without adapting the other parameters, such as tapping frequency, soon exhausts the reserves and leads to bad tissue regeneration resulting in bark dryness and an end to latex production (Eschbach et al. 1989).

\subsection{Our hypothesis: Tapping panel diagnosis is a way} to read and analyse the scars left on the tapping panel during the lifetime of the plantation

Here we explain the two stages of tapping panel diagnosis: the panel history on which the main observations are based and the three indicators on which the analyses are based.

\subsubsection{Panel history}

The diagram of tapping history is the visual basis of the tapping panel diagnosis: It represents the cylindrical area of a rubber tree trunk in two dimensions. As examples, we show the two tapping management models recommended in the study area (Fig. 2): The CDC model is the oldest and has been in use since 1946, whereas the HVC model has only been in use since 1975 and consequently incorporates progress concerning upward tapping and tapping frequency.

The cut length determines the vertical partitioning of the trunk and therefore the number of tapping panels. By observing the relative thickness of regenerating bark on portions of the panel that have already been tapped, it is possible to reconstruct the progression of the tapping cuts over time and the order in which the panels were consumed: This is referred to as panel history. 


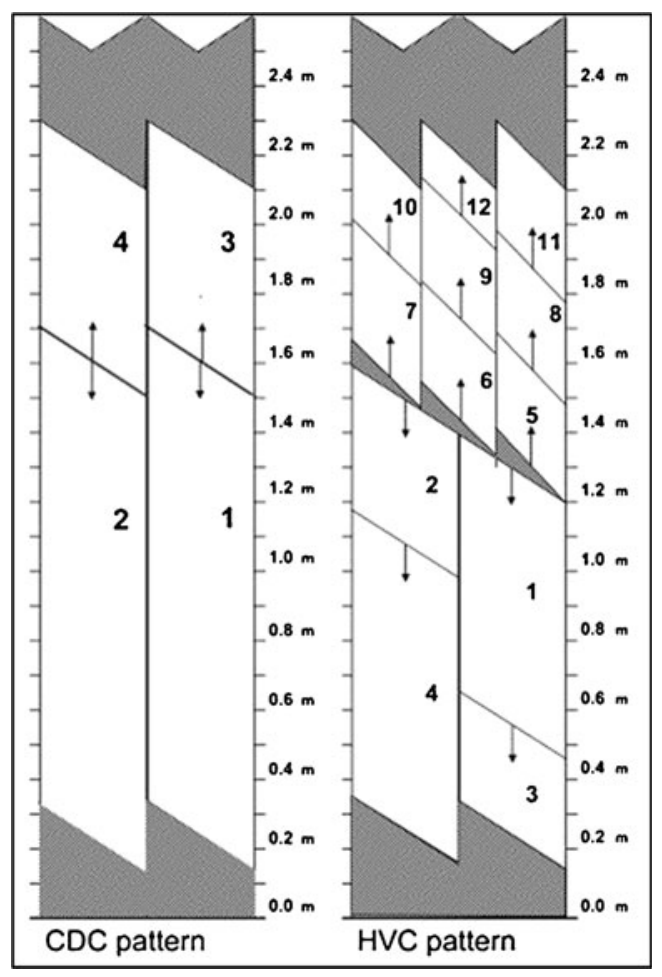

Fig. 2 The tapping panel shows the tapping history of the tree. In the figure, the parts of the panels that are already consumed are in white. The virgin portions of panel are shaded. The arrows indicate the tapping direction (downward arrow downward tapping; upward arrow upward tapping). The numbers indicate the sequence of consumption of the tapping panels. Each sequence is followed by a change of panel

We chose to express virgin and consumed bark as vertical metres of tapping panel. The total area of virgin bark (TVB) available for consumption depends on the lower and upper limits of the tappable zone of the trunk. In our study, we considered $0.15 \mathrm{~m}$ from the ground as the lower limit, above the scion-rootstock junction, and $2.10 \mathrm{~m}$ as the upper limit, as rubber trees are seldom tapped above this height in Cameroon.

In Fig. 2, we show the two tapping management models recommended in the study area by the two major agro-firms, Cameroon Development Corporation (CDC) and HEVECAM (HVC). CDC recommends the panel is opened with a downward half spiral $(\mathrm{S} / 2)$ at a height of $1.50 \mathrm{~m}$ from the ground, while HVC recommends a height of $1.20 \mathrm{~m}$ from the ground. The trunk is then divided into two tapping panels. The CDC model did not originally envisage upward tapping. The high first opening height reflects the aim of maximising the time spent on downward tapping, whereas the HVC model immediately incorporated the idea of upward tapping. HVC thus aimed to maximise the time spent on upward tapping, which is known for its higher yield. Above the first opening height, according to $\mathrm{CDC}$, tapping was to be in an upward direction half-spiral $(\mathrm{S} / 2)$ and according to $\mathrm{HVC}$, in a third-spiral $(\mathrm{S} / 3)$. The upper section of the trunk was then divided into two or three tapping panels. The HVC model (S/3) accounted for the advantage of reducing the cut length when upward tapping is combined with hormonal stimulation (Commère and Eschbach 1988a, b). In the CDC model, tapping frequency was $\mathrm{d} 3$, whereas the HVC model increased from $\mathrm{d} 5$ to $\mathrm{d} 4$ during the lifetime of the plot because stimulation was included from the outset.

\subsubsection{The indicators designed to analyse panel histories}

The panel histories were drawn starting from the average bark consumption on 15 trees. These 15 trees, tapped by the same tapper, were selected randomly in each plot. Trees on which tapping was stopped temporarily or permanently because of bark dryness were disregarded for analysis.

We estimated the economic sustainability of each plot using three indicators belonging to the tapping panel diagnosis: virgin bark consumption (VBC) (1), annual bark consumption (ABC) (2) and the number of remaining tapping years (RTY) on virgin bark (3).

$\operatorname{VBC}\left(\% \mathrm{y}^{-1}\right)=\mathrm{CVB} / \mathrm{TVB} * 100$

Where CVB is the height (in centimetres) of consumed virgin bark measured at diagnosis,

TVB is the height (in centimetres) of total virgin bark available for consumption when the trees were first opened for tapping.

VBC is expressed per tapping year $\left(\% \mathrm{y}^{-1}\right)$ so as to be able to compare plots of different ages.

$$
\begin{aligned}
& \mathrm{ABC}\left(\text { cmyear }^{-1}\right)= \mathrm{ST} * \mathrm{nTC}_{\text {month }}^{-1} \\
& * \text { nTM year } \\
&
\end{aligned}
$$

Where ST (centimetres) is bark shaving thickness,

nTC is the number of tappings per month; this number month $^{-1}$ is directly linked to the tapping frequency and to the number of working days per week ( 6 days in our study areas, $6 \mathrm{~d} / 7$ ),

nTM is the number of tapping months per year; this year $^{-1} \quad$ number is directly linked to the interruptions in tapping over the year: We took into account interruptions during rubber tree defoliation and, in some areas, during the rainy season. This variable was obtained from interviews with the farmers.

RTY (remaining tapping years) $=\mathrm{RVB}(\mathrm{cm}) / \mathrm{ABC}$

Where RVB (centimetres) is the height of the remaining virgin bark, calculated from the panel history. 
When we used RTY to compare different tapping management systems but wanted to avoid variations due to the differences in the skill of the individual tapper, we calculated ABC using a shaving thickness of $2 \mathrm{~mm}$.

When ST was tested as an explanatory variable of VBC, we evaluated the true average by computing ST on a sample of 15 trees.

Although the industrial models allow for a return to tapping on regenerated bark, we considered only virgin bark for two reasons: (1) at the time of the survey, only two plots were being tapped on regenerated bark, and (2) the possibility of a return to regenerated bark depends on the quality of tapping on virgin bark.

\subsection{Study site and plot sampling}

The study site is located in the Southwest Province of Cameroon between the towns of Buéa $\left(4^{\circ} 09^{\prime} \mathrm{N} 9^{\circ} 14^{\prime} \mathrm{E}\right)$, Kumba $\left(4^{\circ} 38^{\prime} \mathrm{N} 9^{\circ} 26^{\prime} \mathrm{E}\right)$, and Mbonge $\left(4^{\circ} 33^{\prime} \mathrm{N} 9^{\circ} 14^{\prime} \mathrm{E}\right)$ and in South Province, south of the axis between Kribi $\left(2^{\circ} 56^{\prime} \mathrm{N} 9^{\circ} 54^{\prime} \mathrm{E}\right)$ and Akok $\left(2^{\circ} 47^{\prime} \mathrm{N} 10^{\circ} 16^{\prime} \mathrm{E}\right)$. The study was carried out on a set of 25 smallholdings distributed throughout the two areas covered by the two main Cameroonian agro-firms CDC and HVC. The rubber tree is one of the main perennial crops for smallholders in these regions and is grown on a total area of 4,000 ha. Smallholders plant high-yielding material provided by the agro-firms along with their own recommended tapping management models.

To adapt and test the tapping panel diagnosis method, we sampled plots representing the widest range of tapping practices rather than sampling the most representative plots. Twenty-five farms were selected based on (1) the size of the rubber plantation and (2) their location. We hypothesised that the size would reflect the farmer's objectives and consequently be linked to technical choices. In addition, as each production area was characterised by one of the two agro-industrial models (CDC or HVC), we assumed that the geographical location would contribute to the diversity of practices. Here, we define a plot as a continuous area planted the same year using the same method, with genetically uniform planting material. We selected the oldest plot on each farm (25 plots) (Table 1) to maximise the length of the period for which we could analyse the practices used.

\subsection{Statistics}

All analyses were performed with $\mathrm{R}$ software ( $\mathrm{R}$. Development Core Team 2005) and the package Companion to Applied Regression (Fox and Weisberg 2010). Multiple linear regression analysis was performed to estimate the weight of each tapping management parameter in bark
Table 1 Characteristics of the 25 farms sampled in Southwest Province, Cameroon, distributed throughout the production areas influenced by the two agro-industrial models (CDC, HVC)

\begin{tabular}{lcc}
\hline Area under rubber per farm, ha & \multicolumn{2}{l}{ Number of farms } \\
\cline { 2 - 3 } & CDC area & HVC area \\
\hline $0.5-5$ & 6 & 1 \\
$>5-10$ & 7 & 4 \\
$>10$ & 4 & 3 \\
Total & 17 & 8 \\
\hline
\end{tabular}

consumption. The multiple linear regression equation gave us an estimation of bark consumption according to the value of each tapping parameter.

These parameters were combined within tapping management systems. In the same way, we used analysis of covariance to assess the impact of the different tapping management systems, together with shaving thickness, on bark consumption. The contribution of each variable to R2 was calculated by dividing sum of square differences explained by a variable by the total sum of square.

\section{Results and discussion}

3.1 Using the tapping panel diagnosis to assess impact of each tapping practices on virgin bark consumption (VBC)

Our results showed high variability of virgin bark consumption ( $\mathrm{VBC} \% \mathrm{y}^{-1}$ ) calculated from the panel histories across the 25 plots (3.9\% to $7.6 \%$ ). Our objective was to identify relations between this variability and the variability of observed farmers' tapping practices.

First, we were able to summarise the variability observed across our plot sample using three tapping system parameters. These parameters, which are known to influence latex production, also influence the economic life span of the trees and their future production potential:

- The number of tapping cuts: several simultaneous cuts vs. respecting recommendations which limit tapping to one cut at a time (Anekachai 1989);

- The length of the cut: exceeding recommended length vs. respecting recommended length; this was particularly the case for upward tapping in the HVC area where many farmers used $\mathrm{S} / 2$ vs. the recommended $\mathrm{S} / 3$;

- The tapping frequency: increasing this parameter vs. respecting recommended frequency, i.e., increasing tapping frequency to $\mathrm{d} 3$ in the HVC area vs. $\mathrm{d} 4$ as recommended, and to $\mathrm{d} 2$ in the CDC area vs. $\mathrm{d} 3$ as recommended. 
We also considered the bark shaving thickness. Although it reflects the tapper's technical skill more than a technical choice, this parameter may explain the variability of VBC.

Covariance analysis of VBC according to the four previously described parameters showed that the tapping cut length did not significantly affect the VBC ( $p$ value $=$ $0.334)$. Variability of this practice was limited to upward tapping cuts. Moreover, as only two slightly contrasted modalities were observed $(\mathrm{S} / 3$ and $\mathrm{S} / 2)$, we removed this parameter from the model and used multiple linear regression to estimate the impact of the other parameters. The resulting equation was:

$\operatorname{VBC}_{i}\left(\% \cdot \mathrm{y}^{-1}\right)=\beta 0+\beta 1 * \mathrm{x} 1_{i}+\beta 2 * \mathrm{x} 2_{i}+\beta 3 * \mathrm{x} 3_{i}+\varepsilon_{i}$

where $i$ is the number of the plot, $i=1,2, \ldots 25$.

$\times 1 \quad$ is the shaving thickness, $\times 2$ : the tapping frequency, $\times 3$ : the number of tapping cuts,

$\varepsilon_{i} \quad$ are independent and identically

$\beta_{0}, \beta_{1}, \beta_{2}$, and $\beta_{3} \quad \begin{aligned} & \text { distributed residual errors, } \varepsilon_{i} \sim \mathrm{N}(0, \sigma \\ & \text { are regression parameters. These }\end{aligned}$ estimated parameters are $\beta_{0}=4.8906(P$, $0.00017) ; \beta_{1}=1.0172(P, 0.000752)$; $\beta_{2}=-1.0805(P, 9.14 \mathrm{e}-05) ; \beta_{3}=0.9664$ $(P, 0.000418)$ where $P$ is the $p$ value for testing the nullity of coefficients.

The three variables significantly affected VBC and explained $75.6 \%$ of the VBC variability $\left(R^{2}=75.6 \%\right)$. Calculating the contribution of each variable to $R^{2}$ made it possible to compare the contribution of each variable to total observed variability. Shaving thickness and tapping frequency explained respectively $28 \%$ and $27 \%$ of the VBC variability, whereas the number of tapping cuts explained $20 \%$ of this variability. This results show that, in our conditions, bark consumption was influenced by both technical choices (tapping frequency, number of tapping cuts) and the skill of the tapper (shaving thickness).

Another parameter was involved in the variability of the panel histories but did not influence bark consumption: the time when upward tapping was started. Among our sampling plots, upward tapping was sometimes started early, i.e., before all the virgin bark on the lower panels had been consumed. In this case, the trunk had a smaller diameter than it would have had a few years later, which may imply a future reduction in yield.

3.2 Using the tapping panel diagnosis to characterise tapping management systems and their impact on VBC

The tapping parameters were then combined in the tapping management systems (TMS) our tapping panel diagnosis had enabled us to identify. Seven TMS of these parameters were identified (Fig. 3).

Only one of the TMS (M2), in the CDC area, corresponded to the agro-industrial recommendations. Six of the TMS (M3 to M7) included at least one modality known to increase tree yield in the short term, to speed up bark consumption, and to reduce the sustainability of plantations.

One TMS (M1) represented tapping practices that were less intensive than the recommended practices. This situation was observed in plots in which the tapping frequency was lower than that recommended, and upward tapping was

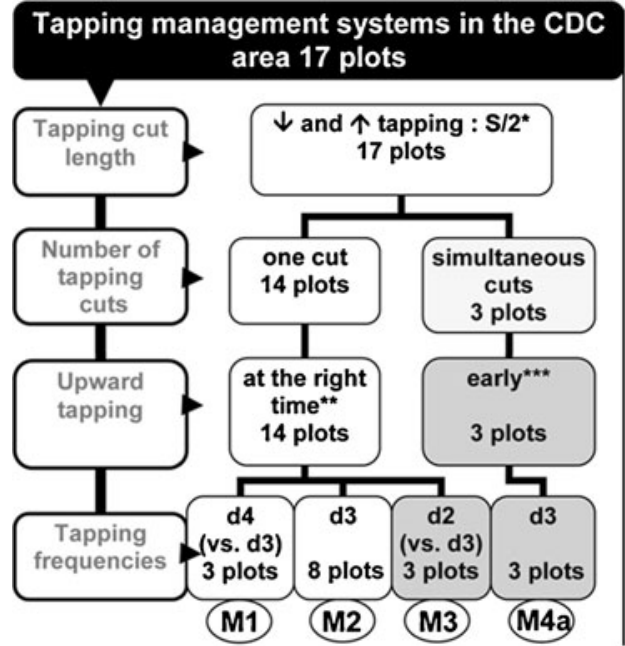

Fig. 3 Tapping management systems observed in the sample of panel diagrams at the time of the survey in each area. The M2 combination respected agro-industrial recommendations in the CDC area. Practices that increased yield are in shaded boxes. The darker the shading, the more practices known to increase crop yield are combined. Downward arrow

\section{Tapping management systems in the HVC} area 8 plots

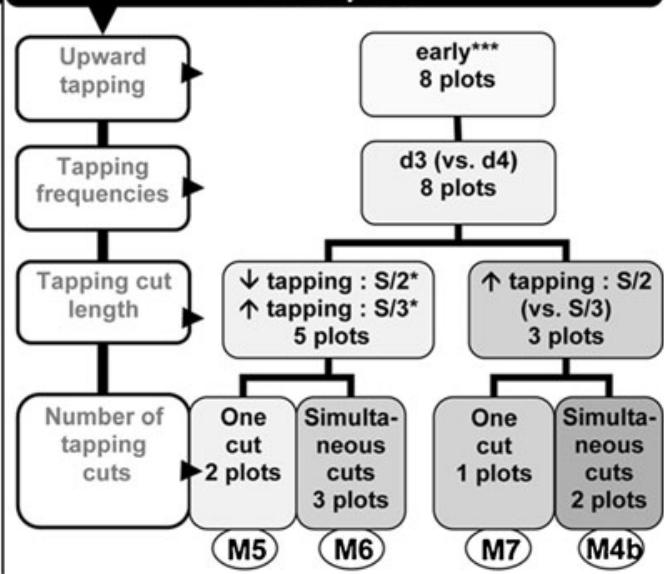

tapping: downward tapping; upward arrow tapping: upward tapping; Asterisk according to the recommendations; double asterisk after virgin bark on the bottom panel was completely consumed; Triple asterisk Before virgin bark on the bottom panel was completely consumed 
delayed. The other TMS (M3, M4a, and $b, \mathrm{M} 6, \mathrm{M} 7)$ were supposed to increase VBC.

The impacts of TMS and shaving thickness on bark consumption were assessed using analysis of covariance. The equation was as follows:

$\operatorname{VBC}_{j}\left(\% . \mathrm{y}^{-1}\right) \sim \beta 0+\beta 1 *$ shaving thickness $+\alpha_{\mathrm{C} i}+\varepsilon_{j}$

where $\alpha_{C i}$ is the coefficient for each combination of $i$ practices; $R^{2}=85 \%$,

$j \quad$ is the number of the plot, $i=1,2, \ldots 25$,

$\varepsilon_{j} \quad$ are independent and identically distributed residual errors, $\varepsilon_{j} \sim N\left(0, \sigma^{2}\right)$,

$i \quad$ is the number of combinations of practices, $i=$ $1,2, \ldots 8$,

$\beta_{0}, \beta_{1}$, and are covariance analysis parameters. $\alpha_{C i}$ is the $\alpha_{C i}$ coefficient for each combination of $i$ practices.

Calculation of the contribution of each variable to $R^{2}$ showed that shaving thickness explained $28 \%$ of VBC variability and combinations of practices explained $57 \%$. Table 2 shows the impact of low tapping frequency (M1) which significantly reduced the VBC, while a high tapping frequency (M3) and double cuts (M4a) significantly increased VBC in the CDC area.

In spite of the differences between the agro-industrial models, the results obtained with combination M5, applied in CDC area, did not differ significantly from those obtained with combination M2, which corresponded to the CDC agro-industrial model. This is partly explained by the use of a single cut and the same tapping frequency in the two combinations. The other combinations had a significant impact on VBC.

Part of the variability recorded among plots may also result from the different lengths of the period of intensified TMS. For example, double tapping cuts were started earlier in the lifespan of plots in the HVC area, which explains why M $4 b$ had a greater impact on VBC than M4a. In the same way, untimely interruptions in tapping are frequent in Cameroon (Chambon and Eschbach 2009) and cause underconsumption of bark whose extent depends on the length of the interruption.
3.3 Using tapping panel diagnosis to calculate remaining tapping years (RTY)

Our results show that tapping panel diagnosis made it possible to calculate the RTY and then to compare the tapping management systems according to their influence on the economic lifespan of the plantation. This made it possible to compare each tapping system with standard models and to explain the consequences of their technical choices to the farmers. We based this calculation on the assumption that the smallholders continued using the same practices as those observed at the time of diagnosis (Fig. 4). For the same number of tapping years, we observed high variability of RTY. This variability reflected different degrees of intensification of the previously analysed tapping management systems. Our result revealed the high impact of tapping frequency on RTY. In the CDC area, the lower the tapping frequency (M1), the higher the plots are located on the graph, i.e., the higher RTY.

From Fig. 4, we were able to deduce the total duration of tapping on virgin bark by adding RTY to the number of past tapping years and compare it to the agro-industrial models.

Our results show that the three plots in which combination M1 was used had an average tapping time saving on the total virgin bark of about 5 years compared with the agro-industrial model. Low tapping frequencies (M1) benefited both plot sustainability and labour productivity. As reported in a study in Côte d'Ivoire (Commère and Eschbach 1988a, b; Jacob et al. 1989), switching from $\mathrm{d} 3$ to $\mathrm{d} 4$ reduced yield by an average of $7 \%$ but led to a $24 \%$ increase in labour productivity

Conversely, tapping management systems including intensification practices (M3 to $\mathrm{M} 7$ ) are located above the line representing the agro-industrial model. After 14 tapping years, virgin bark was completely consumed in plot 6 (M3) where the higher tapping frequency was used (Fig. 4a). Plots in which combination M3 was used showed an average reduction of 4.5 tapping years compared with the CDC model.

The results were more uniform in the HVC area. However, significant differences were observed between the recommended agro-industrial model and the way it was actually applied by growers who systematically intensified tapping management. Their plots are located far below the reference line (Fig. 4b). Early use of intensification practices in the HVC area partly explained this difference.

Table 2 Coefficients resulting from covariance analysis for each component of the equation calculated for the 25 plots in our sample

\begin{tabular}{lllllllllll}
\hline Coefficients & $\beta_{0}$ & $\beta_{1}$ & $\alpha_{\mathrm{M} 1}$ & $\alpha_{\mathrm{M} 2}$ & $\alpha_{\mathrm{M} 3}$ & $\alpha_{\mathrm{M} 4 a}$ & $\alpha_{\mathrm{M} 5}$ & $\alpha_{\mathrm{M} 6}$ & $\alpha_{\mathrm{M} 7}$ & $\alpha_{\mathrm{M} 4 b}$ \\
\hline Value & $2.82^{\mathrm{a}}$ & $0.86^{\mathrm{b}}$ & $-0.7^{\mathrm{c}}$ & 0 & $1.51^{\mathrm{a}}$ & $0.83^{\mathrm{c}}$ & 0.16 & $1.17^{\mathrm{b}}$ & $1.14^{\mathrm{c}}$ & $1.62^{\mathrm{a}}$ \\
\hline
\end{tabular}

Combination M2, which is the only combination that respected CDC agro-industrial recommendations, was used as reference

Significance according to $P$ value results $-0<{ }^{\mathrm{a}}<0.001<^{\mathrm{b}}<0.01<^{\mathrm{c}}<0.05<0.1$ 
a

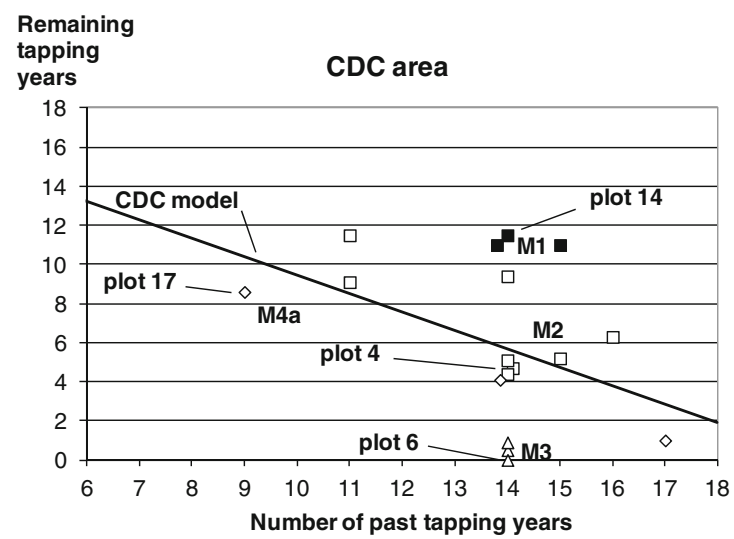

Fig. 4 Remaining tapping years (RTY) of each plot in the CDC (a) and HVC (b) areas, as a function of the number of past tapping years. RTY partly depends on future technical choices. We assumed that the practices observed during the diagnosis would continue to be applied in the same way over time (except bark shaving thickness, which was set at $2 \mathrm{~mm}$ for all plots). For the few plots in the CDC area in which there was no upward tapping, we assumed the adoption of $\mathrm{S} / 2$ as recommended by the agro-

The average tapping time on virgin bark, estimated by adding the number of past tapping years to the remaining tapping years, thus fluctuated between 17 and 19 years. As a consequence, the duration of tapping on virgin bark decreased from $30 \%$ to $40 \%$ compared with the agroindustrial model.

\subsection{Testing bark diagnosis as a decision-support tool}

We show that tapping panel diagnosis can be used as a decision-support tool to: (1) identify innovations to be introduced in the different plots in terms of tapping panel management, and (2) simulate their impact on RTY. For that purpose, we considered four main possible changes, including results already published in the specialised literature:

- Reducing tapping frequency (d4), taking into account the generalised use of hormone stimulation in the study area with specifications adapted to low tapping frequencies (Lacote et al. 2010);

- Reducing tapping cut length in upward tapping (S/4) (Commère and Eschbach 1988a, b);

- Abandoning double cuts (Anekachai 1989);

- Using a more rational succession of panels mainly implies the complete consumption of lower panels before starting upward tapping; indeed, yield from the bottom panels is lower when the bark on the upper panels is already being consumed. Consumed panels reduce sugar availability in latex regeneration areas (Lacote et al. 2004).

For our sample of 25 plots, this simulation was carried out in two steps. First, we used the panel diagram to identify

\section{b}

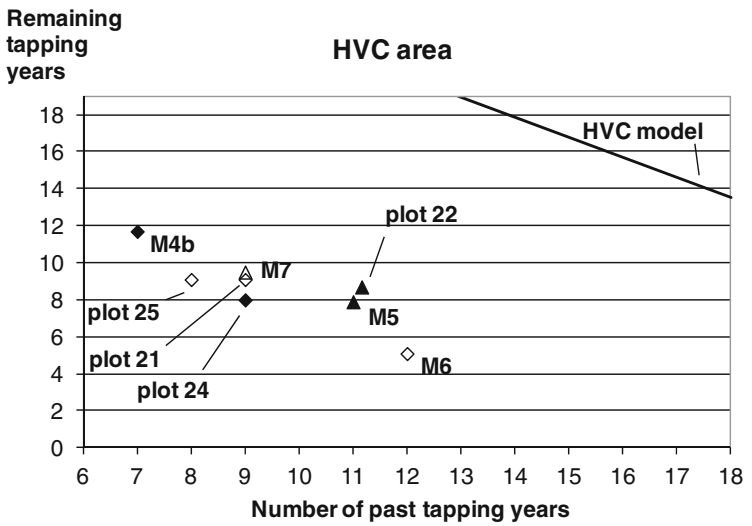

industry at the time of the survey. Changes in RTY over time for each agro-industrial model are represented by the diagonal line. A notable difference appeared between the two agro-industrial models, with a total theoretical tapping duration on virgin bark of 31 years for the HVC model and only 19 years for the CDC model. HVC's choice in favour of reduced tapping frequency and maximum time spent on upward tapping with a shorter cut length are largely responsible for this difference

possible technical changes in the length and number of tapping cuts (Fig. 5).

The succession of panels was redefined in the first step and was likely to influence latex yield but not bark availability. The second step consisted in evaluating the impact of changes by calculating the increase in the height of virgin bark.

The first step (Fig. 5) did not take tapping frequency into account, which had previously appeared to be the main source of increased bark consumption.

As a result, three factors appeared to have an impact on the increase in virgin bark height. The main factor was the adoption of $\mathrm{S} / 4$ in upward tapping. However, two other parameters may limit its application: the degree of bark consumption on the upper panels and the previously used cut length. In plots 14 , 4, and 24 , the existing $\mathrm{S} / 2$ could be divided into two $\mathrm{S} / 4$, resulting in twice the initial height of the remaining tappable bark on the panel concerned. However, in plots 22 and 21, where $\mathrm{S} / 3$ was originally used for upward tapping, the only option was to continue the same practice.

Reducing the original several cuts to only one was another way to increase virgin bark height (plots 17, 21, and 24).

Finally, the amount of virgin bark already tapped at the time of the diagnosis obviously influenced potential improvement and explained why no improvement was obtained in plot 6 , whereas considerable improvement was achieved in plots 14 and 17 (Fig. 5).

The second step (Fig. 6) consisted in using the resulting virgin bark height to calculate the RTY considering a reduction in tapping frequency to $\mathrm{d} 4$. We were then able to evaluate the impact of target innovations on the lifespan of the plots. 


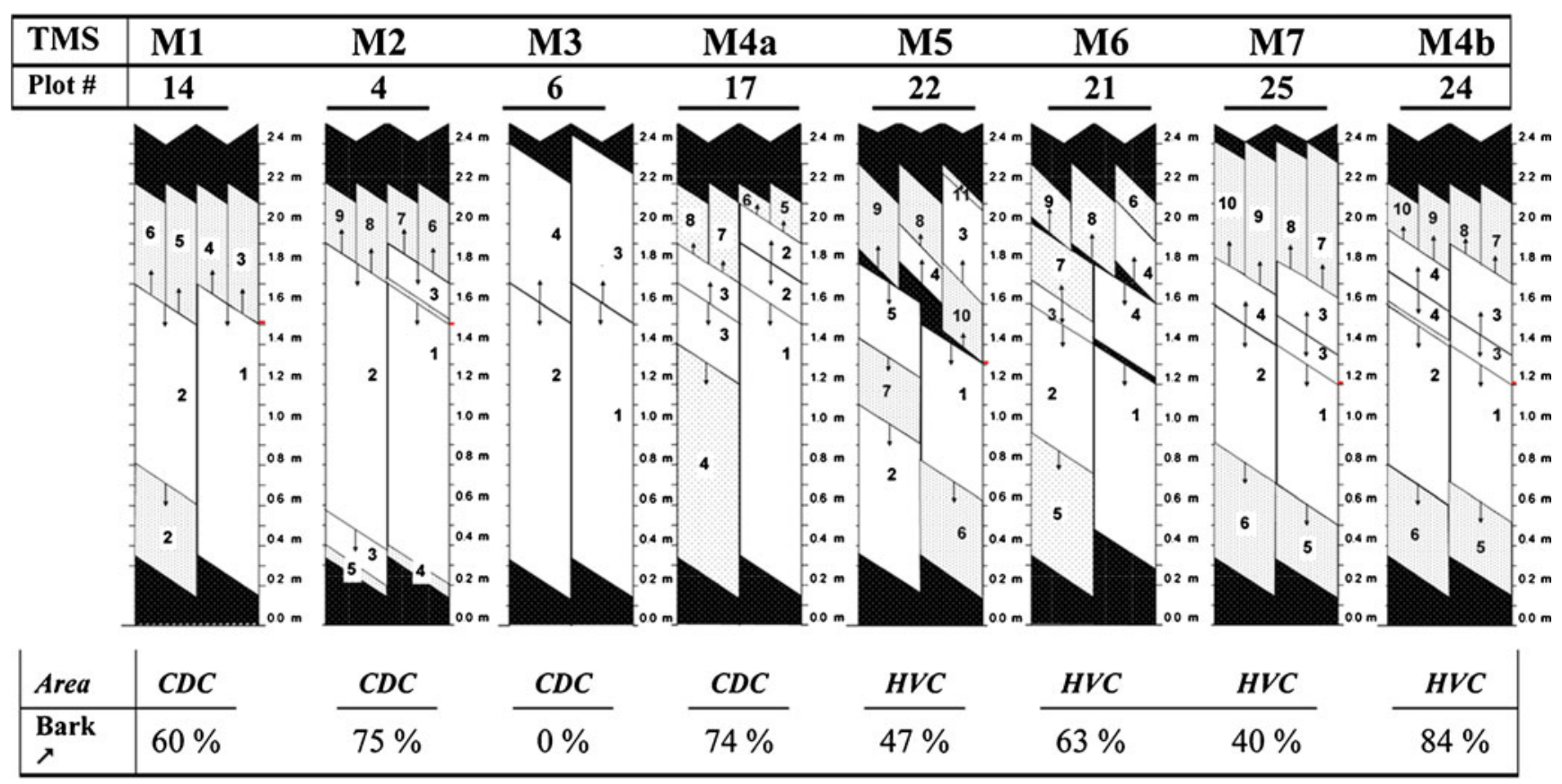

Fig. 5 Examples of tapping panel diagnosis performed on representative cases of tapping management variability and used as a tool to identify and test changes (cut length, panel succession, and number of tapping cuts); the impact of intended changes was identified by measuring the increase

The lengthening of the mean observed lifespan partly depended on the combination of previously used practices (Fig. 6). We showed that combinations including double cut, i.e., M4a and M4b, were those which gave the best performances for a return to less intensive practices in terms of percentage of remaining tapping years with respective increases of $356 \%$ and $284 \%$ in RTY. In the same way, switching from high tapping frequencies to low ones led to a major increase of $220 \%$ in RTY (M3). This change led to both

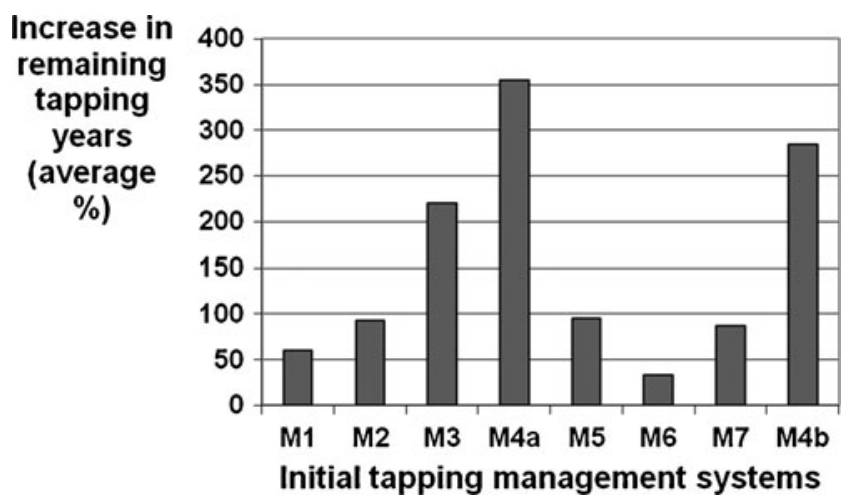

Fig. 6 Average increase in remaining tapping years as a function of the initial tapping management systems. Assessing the impact of technical changes in terms of an increase in the number of remaining tapping years on virgin bark (RTY) is the second step in the use of tapping panel diagnosis as a decision-support tool. To make it possible to compare plots in which the number of past tapping years varied and thus resulted in major fluctuations in RTY, results are expressed as percentage increase in RTY in the height of tappable virgin bark (\%, mean). TMS: Tapping management systems; Bark northeast arrow: increase in virgin bark height; areas in white: panels of already consumed bark; lightly shaded areas: panel of virgin after adoption of changes; dark shaded areas: unusable bark

bark savings and less intensive management favouring the physiological balance of the trees (Jacob et al. 1989; Lacote et al. 2010).

In conclusion, tapping panel diagnosis is easy to use and requires few resources but will need to be adapted to each production area, in accordance with local practices or constraints such as maximum tapping height, which determines virgin bark potential, or the number of working days per week and the number of months tapping is interrupted during the year, which influence annual bark consumption. The tapping panel diagnosis is an appropriate way to evaluate the impacts of tapping management specifications on the virgin bark availability, which is the production capital of the rubber tree. Other parameters, such as hormone stimulation, which influence the physiological status of trees, and the quality of tapping, which influences the likelihood of tapping regenerated bark, could also affect the economic sustainability of the rubber plantation. Although these parameters would be useful supplements in the diagnosis, we chose to base our tool on observable data that we considered reliable. This specification, which is seldom encountered in the diagnosis of tree plantations, makes this tool original. In the same way, focusing the agronomic diagnosis on the economic lifespan of the plantation and not on yield or productivity is also original. But we believe that changes suggested by the use of tapping panel diagnosis as a decision support tool should improve the physiological status of the trees and hence also improve yield in the long run. 
Tapping panel diagnosis is a very visual decision-support tool, which will help smallholders identify a potential innovation and calculate its feasibility. We showed that, in some cases, its use could lead to more than $300 \%$ increase in remaining tapping years. It can consequently be used for participatory research purposes, to identify previous technical choices, to deduce the current potential of the plot, and to design innovating tapping management systems in accordance with the objectives of the smallholders. The simulation of the impact of tapping management systems on the sustainability of a plot is likely to be of interest to decision makers, both at the scale of a group of producers and of a whole supply basin.

\section{Conclusion}

For smallholders, a rubber tree plantation is a major investment, and its sustainability is all the more crucial since the productive period is preceded by a 7-year unproductive immature period. As tapping panel diagnosis is based on observations of the tree, it is a tool easy to use on the farm to identify the practices that have been used since the plot was first opened for tapping. It shows how present or future practices affect the consumption of virgin bark and allows the economic sustainability of the plots to be predicted. In our study, we simulated some changes in technical practices by visualising them on tapping panel diagrams: We showed that they could extend the remaining tapping time by $33 \%$ to $355 \%$. Tapping panel diagnosis can be used by technicians and producers in participatory research projects. In a foresight-type initiative, this tool can help stakeholders estimate short- and medium-term supply trends for a given post-harvest processing unit or, conversely, pinpoint the need for technical assistance by a set of producers in a particular production area. Everywhere in the world where natural rubber is produced, this tool could help achieve the economic sustainability of smallholder plantations. In addition, this tool, which was designed for the rubber tree, could serve as a basis for designing similar tools for other tapped tree species.

\section{References}

Affholder F, Scopel E, Madera Neto J, Capillon A (2003) Diagnosis of the productivity gap using a crop model. Methodology and case study of small-scale maize production in central Brazil. Agronomie 23:305-325

Anekachai C (1989) Tapping systems approach for smallholders in Southern Thailand. The Franco-Thai Workshop on natural rubber tapping practices on smallholdings in Southern Thailand. Patthavuh Jewtragoon, Hat-Yai, pp 27-31
Ballal M, El Siddig E, Elfadl M, Luukkanen O (2005) Gum arabic yield in differently managed acacia senegal stands in western Sudan. Agroforest Syst 63:237-245

Chambon B, Eschbach JM (2009) Marketing of smallholder natural rubber: an essential factor in the development of Cameroonian rubber-growing. Cah Agric 18:364-368

Chatelin MH, Aubry C, Poussin JC, Meynard JM, Massé J, Verjux N, Gate P, Le Bris X (2005) Déciblé, a software package for wheat crop management simulation. Agr Syst 83:77-99

Commère J, Eschbach JM (1988) The advantages of low intensity upward tapping in Côte d'Ivoire. CR Coll Expl Physiol Amél Hévéa

Commère J, Eschbach JM (1988b) Résultats des essais de réduction de fréquence de saignée en Côte d'Ivoire. In: Prévôt JC, Jacob JL (eds) CR Coll Expl Physiol Amél Hévéa. CIRAD-IRCA, Montpellier, pp 321-333

Compagnon P (1986) Le Caoutchouc Naturel-Biologie-Culture-Production. Maisonneuve et Larose, Paris

R. Development Core Team (2005) R: a language and environment for statistical computing. Vienna, Austria

Doré T, Sebillotte M, Meynard JM (1997) A diagnostic method for assessing regional variations in crop yield. Agr Syst 54:169-188

Doré T, Clermont-Dauphin C, Crozat Y, David C, Jeuffroy MH, Loyce C, Makwski D, Malezieux E, Meynard JM, Valentin-Morison M (2008) Methodological progress in on-farm regional agronomic diagnosis. A review. Agron Sustain Dev 28:151-161

Eschbach JM, Banchi Y (1985) Advantages of ethrel stimulation in association with reduced tapping intensity in the Ivory Cost. Planter (MYS) 61:555-567

Eschbach JM, Lacrotte R, Serres E (1989) Conditions which favor the onset of brown bast. In: d'Auzac J, Jacob JL, Chrestin H (eds) Physiology of rubber tree latex. CRC, Boca Raton, pp 443-454

Fox J, Weisberg S (2010) An R companion to applied regression. Sage, Thousand Oaks (CA-USA)

Gras R, Benoit M, Deffontaines JP, Duru M, Lafarge M, Langlet A, Osty PL (1989) Le fait technique en agronomie-Activité agricole, concepts et méthodes d'étude. INRA, PARIS

IRSG (2010) Rubber statistical bulletin. The International Rubber Study Group, Singapore, p 55

Jacob JL, Prévôt JC, Roussel D, Lacrotte R, Serres E, d'Auzac J, Eschbach JM, Omont H (1989) Yield limiting factors, latex physiological parameters, latex diagnosis and clonal typology. In: d'Auzac J, Jacob JL, Chrestin H (eds) Physiology of rubber tree latex. CRC, Boca Raton, pp 345-403

Lacote R, Obouayeba S, Clément-Demange A, Dian K, Gnagne M, Gohet E (2004) Panel management in rubber (Hevea brasiliensis) tapping and impact on yield, growth, and latex diagnosis. J Rubber Res 7:199-217

Lacote R, Gabla O, Obouayeba S, Eschbach JM, Rivano F, Dian K, Gohet E (2010) Long-term effect of ethylene stimulation on the yield of rubber trees is linked to latex cell biochemistry. Field Crop Res 115:94-98

Le Bail M, Meynard JM (2003) Yield and protein concentration of spring malting barley: the effects of cropping systems in the Paris Basin (France). Agronomie 23:13-27

Lemenih M, Abebe T, Olsson M (2003) Gum and resin resources from some Acacia, Boswellia and Commiphora species and their economic contributions in Liban, south-east Ethiopia. J Arid Environ $55: 465-482$

Lichtfouse E, Navarrete M, Debaeke P, Souchère V, Alberola C (2009) Sustainable agriculture. Springer, Heidelberg

Meynard JM, Cerf M, Guichard L, Jeuffroy M-H, Makowski D (2002) Which decision support tools for the environmental management of nitrogen? Agronomie 22:817-829

Michels T (2005) Adapter la conduite des plantations d'hévéa à la diversité des exploitations villageoises (étude de cas au 
Cameroun). Ecole doctorale ABIES, Institut National Agronomique Paris-Grignon, Paris

Nesme T, Lescourret F, Bellon S, Plénet D, Habib R (2003) Relevance of orchard design issuing from growers' planting choices to study fruit tree cropping systems. Agronomie 23:651-660

Nesme T, Lescourret F, Bellon S, Habib R (2010) Is the plot concept an obstacle in agricultural sciences? A review focussing on fruit production. Agr Ecosyst Environ 138:133-138

Obouayeba S, Coulibaly LF, Gohet E, Yao TN, Ake S (2009) Effect of tapping systems and height of tapping opening on clone PB 235 agronomic parameters and it's susceptibility to tapping panel dryness in south-east of Côte d'Ivoire. J Appl Biosci 24:15351542

Plénet D, Giauque P, Navarro E, Millan M, Hilaire C, Hostalnou E, Lyoussoufi A, Samie J-F (2009) Using on-field data to develop the EFI information system to characterise agronomic productivity and labour efficiency in peach (Prunus persica L. Batsch) orchards in France. Agric Syst 100:1-10

Silpi U, Lacointe A, Kasempsap P, Thanysawanyangkura S, Chantuma P, Gohet E, Musigamart N, Clément A, Améglio T, Thaler P
(2007) Carbohydrate reserves as a competing sink: evidence from tapping rubber trees. Tree Physiol 27:881-889

Vijayakumar KR, Thomas KU, Rajagopal R (2000) Tapping. In: Georges PJ, Jacob KC (eds) Natural rubber, agro management and crop processing. Rubber Research Institute of India, Kottayam, pp 215-238

Vijayakumar KR, Thomas KU, Rajagopal R, Karunaichamy K (2001) Low frequency tapping systems for reductions in cost of production of natural rubber. Planters' Chron 97:451-454

Vijayakumar KR, Thomas KU, Rajagopal R, Karunaichamy K (2003) In: Vijayakumar KR, Thomas KU, Rajagopal R, Karunaichamy K (eds) Proceedings of the International Workshop on Exploitation Technology. Rubber Research Institute of India, Kottayam, pp $17-42$

Vijayakumar KR, Gohet E, Thomas KU, Xiaodi W, Sumarmadji LRSL, Thanh DK, Pichit S, Karunaichamy K, Mohd Akbar MDS (2009) Revised international notation for latex harvest technology. J Rubb Res 12:103-115

Webster CC, Baulkwill WJ (1989) Rubber. Longman Scientific and Technical, Harlow 